\section{SAT0241 HEALTH ECONOMIC EVALUATION OF ROFECOXIB VERSUS CONVENTIONAL NSAIDS IN THE TREATMENT OF OSTEOARTHRITIS IN SWITZERLAND}

${ }^{1} \mathrm{SX}$ Kong, ${ }^{2} \mathrm{JM}$ Pellissier. 'Outcomes Research, Merck \& Co., Inc., Whitehouse Station, NJ, USA; ${ }^{2}$ Health Economic Statistics, Merck Research Laboratories, Blue Bell, PA, USA

\subsection{6/annrheumdis-2001.877}

Background In randomised clinical trials, patients with osteoarthritis (OA) who received rofecoxib developed fewer clinically significant gastrointestinal (GI) adverse events than those received conventional NSAIDs.

Objectives We estimated the economic implications of these results in Switzerland.

Methods A model-based cost-effectiveness analysis was conducted, focusing on events related to serious GI complications (perforations, ulcers or bleeds or PUBs) and minor GI problems (e.g. dyspepsia) that imply healthcare resource use. The base case analysis had a one-year horizon. GI event probabilities were obtained from a pre-specified pooled analysis of the clinical trials of rofecoxib. The NSAID comparator was an aggregate of those commonly used in Switzerland. To extrapolate trial results to clinical practice, resource utilisation profiles for inpatient and outpatient care of GI events were developed using both the literature and expert opinions in UK, the United States and Canada. Weighted average drug costs of currently reimbursed medications were derived from IMS Health data. It was assumed that $20.6 \%$ of conventional NSAID users needed gastroprotective agents (GPAs) prophylactically based on published data in the UK and other countries. Efficacy of concomitant use of GPAs in preventing NSAID-associated PUBs was inferred from the literature. A $75 \%$ reduction in prophylactic GPA prescription rates with VIOXX was assumed for the base case. Sensitivity analyses explored the effects of varying drug costs, efficacy of GPAs and rates of concomitant GPA use.

Results Our base case analysis showed that in Switzerland, it would save 0.64 Swiss Francs per patient per day by switching conventional NSAIDs to rofecoxib for the treatment of OA. The iatrogenic cost factor for NSAIDs was 1.75 . Results were robust over a range of model assumptions. The cost per PUB avoided ranged from an added cost of 5,951 Swiss Francs (assuming 0\% of GPA use with NSAIDs) to a saving of 16,013 (assuming $50 \%)$, with a saving of 2,522 Swiss Francs at base case $(20.6 \%$ GPA use with NSAIDs).

Conclusion Based upon this analysis of serious and minor GI events for OA patients in Switzerland, rofecoxib represents a cost-effective therapeutic option compared to NSAIDs due to cost savings in GI problems and reduction in use of GPAs.

\section{SAT0242 ANAKINRA INCREASES DAYS OF WORK AND DOMESTIC ACTIVITY IN PATIENTS WITH RHEUMATOID ARTHRITIS}

${ }^{1} \mathrm{~B}$ Bresnihan, ${ }^{2} \mathrm{WW}$ Chan, ${ }^{2} \mathrm{JM}$ Woolley. 'Department of Rheumatology, St Vincent's University Hospital, Dublin, Ireland; ${ }^{2}$ Amgen, Inc., Thousand Oaks, USA

\subsection{6/annrheumdis-2001.878}

\section{Background}

Objectives To evaluate the effect of anakinra treatment on days of work and domestic activity in patients with rheumatoid arthritis (RA).

Methods In a six-month, placebo-controlled study conducted in Europe, 473 patients with RA were randomised to receive anakinra 30,75 or $150 \mathrm{mg} /$ day or placebo. Days of work and domestic activity were evaluated at baseline and after 4, 8, 12, 16, 20, and 24 weeks of therapy using an economic resource survey. The total days of work and domestic activity gained after commencing treatment were quantified as productivity and compared in patients receiving placebo or anakinra.

Results Patients receiving anakinra demonstrated greater gains in productivity for all doses examined (see table). These gains occurred rapidly, with over a two-day gain by week 8 , and over 13 days gained on completion of the study. Furthermore, at the end of the study, an additional $14 \%$ of patients receiving anakinra did not miss any work or domestic activity, compared to $6 \%$ receiving placebo (data not shown) Table 1 . Productivity (Work and Domestic Activity) Days Gained:

\begin{tabular}{|c|c|c|c|c|c|}
\hline & Placebo & $30 \mathrm{mg}$ & $75 \mathrm{mg}$ & $150 \mathrm{mg}$ & All anakinra \\
\hline Week 0-4 & 0.22 & 1.64 & 1.66 & 1.83 & 1.71 \\
\hline Week 4-8 & 0.81 & 2.17 & 2.27 & 2.62 & 2.35 \\
\hline Week 8-12 & 0.74 & 1.61 & 1.98 & 2.63 & 2.06 \\
\hline Week 12-16 & 0.72 & 2.03 & 2.33 & 3.05 & 2.46 \\
\hline Week 16-20 & 1.08 & 2.56 & 2.48 & 3.21 & 2.74 \\
\hline Week 20-24 & 0.02 & 1.61 & 2.20 & 2.33 & 2.04 \\
\hline Total & 3.55 & 11.62 & 12.93 & $15.66^{*}$ & $13.37^{*}$ \\
\hline
\end{tabular}

Conclusion Patients receiving anakinra treatment experienced rapid and dose-related increases in days of work and domestic activity.

\section{SAT0243 THE EFFECT ON TOXICITY OF REDUCING THE SIZE OF AVAILABLE PARACETAMOL PACK SIZES IN THE UNITED KINGDOM}

${ }^{1} \mathrm{CL}$ Sheen, ${ }^{2} \mathrm{JF}$ Dillon, ${ }^{3} \mathrm{DN}$ Bateman, ${ }^{4} \mathrm{~K}$ Simpson, ${ }^{1} \mathrm{TM}$ MacDonald. ${ }^{1}$ Medicines Monitoring Unit, University of Dundee; ${ }^{2}$ Department of Gastroenterology, Ninewells Hospital and Medical School, Dundee; ${ }^{3}$ Scottish Poisons Information Bureau; ${ }^{4}$ Scottish Liver Transplant Unit, Edinburgh Royal Infirmary, Edinburgh, UK

\subsection{6/annrheumdis-2001.879}

Background Analgesia, using such drugs as paracetamol, is vital in the treatment of arthritis. Unfortunately, the incidence of paracetamol overdose, a common cause of hepatotoxicity and death, has been increasing. In the United Kingdom as a means of reducing adverse event risk, the Medicines Control Agency (MCA) limited the pack size of over-the-counter paracetamol in September 1998. This reduction in the amount that can be purchased may make obtaining paracetamol more difficult for people with arthritis.

Objectives To determine paracetamol overdose rates for patients presenting to Ninewells Hospital, Dundee and to assess whether the action by the MCA has had any measurable effect.

Methods Using serum paracetamol levels as a robust marker for overdose, the biochemistry database was searched for all paracetamol assay requests for each 12-month period from September 1995 to September 2000. We recorded all requests, all assays with measurable paracetamol and results that were potentially hepatotoxic $4 \mathrm{~h}$ after ingestion $(>1.3 \mathrm{mmol} / \mathrm{l})$. The numbers of presentations of paracetamol overdose were compared before and after September 1998. 